\title{
Prevalence and predictors of food insecurity among low-income households in Los Angeles County
}

\author{
Bruce W Furness ${ }^{1,2, *}$, Paul A Simon ${ }^{2}$, Cheryl M Wold ${ }^{2}$ and Johanna Asarian-Anderson ${ }^{2}$ \\ 'Preventive Medicine Residency, DAPHT/EPO/CDC, 717 14th Street NW, Suite 950/Box 14, Washington, DC \\ 20005, USA: ${ }^{2}$ Los Angeles County Department of Health Services, USA
}

Submitted 3 July 2003: Accepted 27 January 2004

\begin{abstract}
Objectives: To assess the prevalence and identify the predictors of food insecurity among households in Los Angeles County with incomes below 300\% of the federal poverty level.

Methods: The Six-Item Short Form of the US Department of Agriculture's Household Food Security Scale was used as part of a 1999 county-wide, population-based, telephone survey.

Results: The prevalence of food insecurity was $24.4 \%$ and was inversely associated with household income. Other independent predictors of food insecurity included the presence of children in the household (odds ratio (OR) 1.7, 95\% confidence interval (CI) 1.2-2.3) and a history of homelessness in the past five years (OR 5.6, 95\% CI 3.4-9.4).

Conclusion: Food insecurity is a significant public health problem among low-income households in Los Angeles County. Food assistance programmes should focus efforts on households living in and near poverty, those with children, and those with a history of homelessness.
\end{abstract}

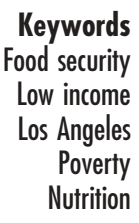

Keywords

ood security

os Angeles

Poverty

Nutrition
Over the past two decades, food insecurity has increasingly been recognised as a serious public health problem in the developed world ${ }^{1}$. In USA, an estimated 12 million households, or $11.1 \%$ of all households, experienced food insecurity in $2002^{2}$, defined as limited or uncertain availability of nutritionally adequate and safe foods, or limited or uncertain ability to acquire acceptable foods in socially acceptable ways ${ }^{3}$.

Potential public health consequences of food insecurity include hunger, malnutrition, and reduced health and quality of life ${ }^{4}$. Low levels of vitamin A, folate, iron and magnesium intake associated with severe food insecurity increase the risk of nutrient deficiencies ${ }^{5}$. Food insecurity has also been associated with compromised psychosocial functioning among low-income school-aged children in two large urban areas of the USA ${ }^{6}$.

National surveys have found considerable variation in the prevalence of food insecurity across states. For example, in 2000-2002, prevalence rates ranged from a low of $6.4 \%$ in Massachusetts to $15.2 \%$ in Utah, and were generally higher among states in the southern region of the country ${ }^{2}$. Although these national and state estimates provide important benchmarks, few data are available on food insecurity at the municipal or county level, where food programmes are most often implemented. The paucity of population-level data on food insecurity in urban settings is of particular concern given the high rates of poverty in these communities. A recent survey in California found that of 2.2 million low-income adults in the state who experienced food insecurity in 2001, more than one-third resided in Los Angeles County ${ }^{7}$.

In this study, we used a validated food insecurity scale ${ }^{8}$ to estimate the prevalence of food insecurity among lowincome households in Los Angeles County and to identify predictors of food insecurity in this high-risk population.

\section{Methods}

A county-wide, population-based telephone survey collected information on sociodemographic characteristics, health status, health behaviours and access to health services among adults and children in Los Angeles County between September 1999 and April 20009. During March and April 2000, a follow-up survey was conducted among those households that had reported an annual income below 300\% of the 1999 federal poverty level (FPL) in the initial survey. For a household with two adults and two dependants, this was equivalent to an annual income of less than $\$ 50685$.

Of households identified as eligible based on their reported annual household income, 1898 (55.4\%) completed the follow-up survey. Of the remaining eligible households, most were lost to follow-up. Respondents were administered the Six-Item Short Form of the US 
Department of Agriculture's (USDA) Household Food Security Scale, which has been shown to be a valid measure of food security (Table 1$)^{8}$. An updated version of the form is now available in which the questions have been reordered $^{3}$; however, this revised version was not available at the time of our study. Additional information was obtained on the presence of children (under 18 years of age) in the household, receipt of public assistance, and experience with homelessness in the past five years. Public assistance included California's Welfare-to-Work programme (CalWORKs), food stamps, Supplemental Food Program for Women, Infants, and Children (WIC), General Relief, or any other federal, state or county payment.

Households were classified as 'food-insecure' if the respondent answered affirmatively to two or more of the six household food security questions. 'Almost every' and 'some months' were considered affirmative responses to Question 2. 'Often' and 'sometimes' were considered affirmative responses to Questions 5 and $6^{8}$.

Table 1 Six-Item Short Form of the US Department of Agriculture's Household Food Security Scale

1. In the last 12 months, did you or any other adults in your household ever have to cut the size of your meals or skip meals entirely because there wasn't enough money for food?
a. Yes
b. No
c. Don't know
d. Refused

2. How often did this happen?
a. Almost every month
b. Some, but not every month
c. Only one or two months
d. Don't know
e. Refused

3. In the last 12 months, did you ever eat less than you felt you should because there wasn't enough money to buy food?
a. Yes
b. No
c. Don't know
d. Refused

4. In the last 12 months, were you ever hungry but didn't eat because you could not afford enough food?
a. Yes
b. No
c. Don't know
d. Refused

5. The food that I/we bought just didn't last, and I/we didn't have money to get more. Was this often, sometimes, or never true for you or the other members of your household in the last 12 months?
a. Often
b. Sometimes
c. Never
d. Don't know
e. Refused

6. I/we couldn't afford to eat balanced meals. Was this often, sometimes, or never true for you or the other members of your household in the last 12 months?
a. Often
b. Sometimes
c. Never
d. Don't know
e. Refused

Data were weighted by age group, race/ethnicity, sex and geographic region, using 1999 Los Angeles County population estimates to adjust for differential participation rates across demographic groups. To examine the association between food insecurity and selected characteristics, the chi-square test and unconditional logistic regression modelling were done using Epi Info (Centers for Disease Control and Prevention, Atlanta, GA, USA) Version 6.04d and SAS (SAS Institute Inc., Cary, NC, USA) Version 8.2, respectively. Food insecurity was used as the dependent variable and the following were used as independent variables: self-reported annual household income (<100\% FPL, 100-199\% FPL, 200-299\% FPL), race/ethnicity (white, Latino, African-American, Asian/Pacific Islander), presence of children in the household, current use of public assistance, and past homelessness. The Hosmer and Lemeshow goodness-of-fit test was used to test the model fit and Wald confidence intervals were used for the adjusted odds ratios.

\section{Results}

Food insecurity was reported by $24.4 \%$ of households. The prevalence of food insecurity decreased with increasing household income. Food insecurity was reported by $34.7 \%$ of households living below 100\% FPL, $23.7 \%$ of households at 100-199\% FPL, and $15.8 \%$ of households at 200 299\% FPL (Table 2).

The prevalence of food insecurity was higher among African-American (32.8\%) and Latino (28.4\%) respondents than among white (17.3\%) and Asian/Pacific Islander (10.9\%) respondents. In addition, the prevalence of food insecurity was higher among households with children

Table 2 Prevalence of food insecurity by selected household characteristics

\begin{tabular}{|c|c|c|}
\hline Household characteristic & $\begin{array}{c}\text { Prevalence } \\
(\%)\end{array}$ & $P$-value \\
\hline \multicolumn{3}{|l|}{ Income* } \\
\hline $200-300 \%$ FPL $(n=544)$ & 15.8 & - \\
\hline $100-200 \%$ FPL $(n=741)$ & 23.7 & $<0.001$ \\
\hline$<100 \%$ FPL $(n=502)$ & 34.7 & $<0.001$ \\
\hline \multicolumn{3}{|l|}{ Race/ethnicity $\dagger$} \\
\hline White $(n=541)$ & 17.3 & - \\
\hline Latino $(n=869)$ & 28.4 & $<0.001$ \\
\hline African-American $(n=218)$ & 32.8 & $<0.001$ \\
\hline Asian/Pacific Islander $(n=80)$ & 10.9 & 0.179 \\
\hline \multicolumn{3}{|l|}{ Children in household } \\
\hline Yes $(n=858)$ & 28.4 & - \\
\hline No $(n=549)$ & 16.3 & $<0.001$ \\
\hline \multicolumn{3}{|l|}{ Public assistance } \\
\hline Yes $(n=209)$ & 36.4 & - \\
\hline No $(n=1573)$ & 22.7 & $<0.001$ \\
\hline \multicolumn{3}{|l|}{ Past homelessness $¥$} \\
\hline Yes $(n=116)$ & 56.4 & - \\
\hline No $(n=1588)$ & 22.3 & $<0.001$ \\
\hline
\end{tabular}

$\mathrm{FPL}$ - federal poverty level.

* $100-200 \%$ FPL and $<100 \%$ FPL versus $200-300 \%$ FPL.

† Latino, African-American and Asian/Pacific Islander all versus white. $\ddagger$ Within the past five years. 
$\square$ With children $\square$ Without children

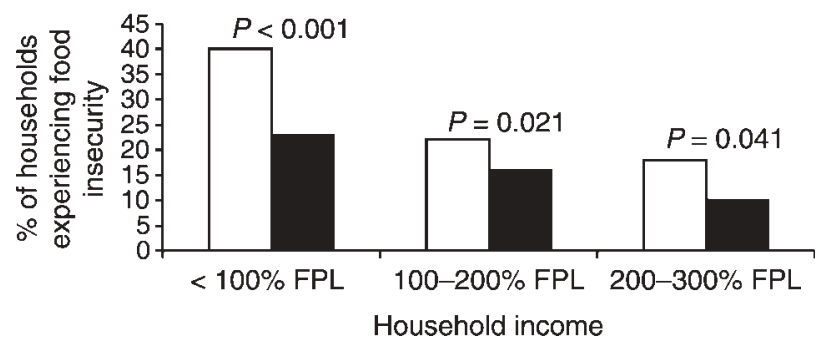

Fig. 1 The prevalence of food insecurity by household income and the presence of children. FPL - federal poverty level

Table 3 Independent variables associated with food insecurity

\begin{tabular}{lc}
\hline Independent variable* & OR $(95 \% \mathrm{CI}) \dagger$ \\
\hline Incomeł & \\
$\quad<100 \% \mathrm{FPL}$ & $3.0(2.0-4.5)$ \\
$100-200 \% \mathrm{FPL}$ & $1.6(1.1-2.4)$ \\
Race/ethnicity§ & \\
$\quad$ Latino & $1.4(0.9-2.1)$ \\
African-American & $1.3(0.8-2.2)$ \\
Asian/Pacific Islander & $0.3(0.1-1.0)$ \\
Children in household & $1.7(1.2-2.3)$ \\
Public assistance & $0.8(0.6-1.2)$ \\
Past homelessness & $5.6(3.4-9.4)$ \\
\hline
\end{tabular}

$\mathrm{OR}$ - odds ratio; $\mathrm{Cl}$ - confidence interval; $\mathrm{FPL}$ - federal poverty level. ${ }^{*}$ Dependent variable is food insecurity.

† Wald Cls for adjusted OR.

$\ddagger<100 \%$ FPL and $100-200 \%$ FPL versus $200-300 \%$ FPL.

$\S$ Latino, African-American and Asian/Pacific Islander all versus white.

I Within the past five years.

(28.4\%) than among households without children (16.3\%). This difference was observed across all income groups, with the highest prevalence among households with children and with incomes below the FPL (Fig. 1). The prevalence of food insecurity was also higher among households receiving public assistance (36.4\%) and reporting past homelessness (56.4\%), compared with households not receiving public assistance (22.7\%) and not reporting past homelessness (22.3\%).

Independent predictors of food insecurity were income $<100 \%$ FPL (odds ratio (OR) 3.0, 95\% confidence interval (CI) 2.0-4.5) and income 100-200\% FPL (OR 1.6, 95\% CI 1.1-2.4), with income 200-300\% FPL as the reference group for both; having children in the household (OR 1.7, 95\% CI 1.2-2.3); and past homelessness (OR 5.6, 95\% CI 3.4-9.4) (Table 3). Asian/Pacific Islander race was associated with a lower prevalence of food insecurity (OR 0.3, 95\% CI 0.1-1.0).

\section{Discussion}

This is the first population-based study to use the Six-Item Short Form of the USDA's Household Food Security Scale to estimate the prevalence and identify predictors of food insecurity in a local public health jurisdiction. Although several studies have examined the relationship between food insecurity and important health and nutrition outcomes in the USA, few have used a valid and reliable measure of food insecurity relevant to food-rich countries, and even fewer have tried to quantify the burden of food insecurity at the local population level.

Our estimate of the prevalence of food insecurity among low-income households in Los Angeles County is consistent with the findings of a prior survey of lowincome adults in the county, although our study included a more expanded definition of low income ${ }^{7}$. In addition, the prevalence in the county is more than twice the rates reported in the general population, both nationally and in California $^{2}$. If we assume that no households in the county with incomes at or above 300\% FPL experienced food insecurity, the prevalence remains approximately 35\% higher in Los Angeles County than nation-wide. A recent study examined hunger among legal immigrants in California, Texas and Illinois, and found that $80 \%$ of households were food-insecure using a more detailed USDA food security scale ${ }^{10}$. However, that study was limited to a convenience sample of 630 respondents and therefore may have limited generalisability.

Previously reported predictors of food insecurity include low income, drug use, receipt of food stamps, a reduction in food stamps, Latino ethnicity, and poor English-speaking ability $^{10-12}$. Our results show that, among households surveyed in Los Angeles County, independent predictors of food insecurity include low income but not Latino ethnicity or use of public assistance. As in other studies, the prevalence of food insecurity was significantly lower among Asians/Pacific Islanders. We also found that having children in the household and past homelessness were both significantly associated with food insecurity, findings that are consistent with those of several other studies $^{2,13}$.

The findings in this report are subject to the following limitations. First, the results are based on a short form of the 18-item Household Food Security Scale. Although this short form has been shown to be a useful tool to assess food insecurity, it may have missed some food-insecure households that the long form would have correctly identified.

Second, the low survey participation rate (55.4\%) may have introduced non-response bias. For example, participating households were less likely to report incomes $<100 \%$ FPL or to be Asian/Pacific Islander and Latino, and were more likely to be white, without children and receiving public assistance. However, the data were weighted using census-based population estimates to reduce potential bias by making the sample more comparable to the county population living below 300\% FPL. Although income was not included in the weighting procedure, race/ethnicity was included and would be expected to reduce some of the bias introduced by differential participation across income groups.

Third, telephone surveys are subject to coverage bias from non-inclusion of households without telephones. 
Lack of telephone service is more common among lowincome households than among other income groups, so they may not be adequately represented in this survey. Therefore, we may have missed those households at highest risk of food insecurity.

Fourth, the race/ethnicity findings are limited because we collected race/ethnicity information on the respondent only and, therefore, were not able to identify mixed race/ethnicity households. Finally, we did not collect information on specific types of public assistance programme participation and, therefore, were only able to assess public assistance as a dichotomous variable in our analysis.

Although food insecurity affects people of all ages, it is of particular concern for pregnant women, children, elderly persons and other nutritionally vulnerable subgroups $^{14}$. In Los Angeles County, where food insecurity is a significant public health concern, the prevalence was higher among three such vulnerable subgroups - those households with the lowest income, those with children, and those that have experienced homelessness within the past five years. Data such as these can be used to guide food assistance programming and highlight the importance of targeting efforts to those who are most vulnerable.

Furthermore, food insecurity appears to affect a larger segment of the population than is included in federal assistance programmes. The prevalence of food insecurity in Los Angeles County among households at 200-299\% FPL was $15.8 \%$, yet the federal standard for food stamp eligibility is a household income less than 130\% FPL. High housing costs, low-paying jobs, high utility costs, unavailability of transportation and problems associated with access to food may all affect the prevalence of food insecurity in urban settings ${ }^{15}$. Data such as these can therefore be used to lobby for expansion of eligibility for food assistance programmes in high-risk settings and for additional local interventions that target vulnerable subpopulations not currently covered by federal programmes.

\section{Acknowledgements}

Support for the survey was provided by the California Department of Health Services, the Los Angeles County Department of Public Social Services, and the Los Angeles County Medicaid Demonstration Project. In addition, Waley Zeng provided invaluable statistical support.

\section{References}

1 Tarasuk V. A critical examination of community-based responses to household food insecurity in Canada. Health Education \& Behavior 2001; 28: 487-99.

2 Nord M, Andrews M, Carlson S. Household Food Security in the United States, 2002. Food Assistance and Nutrition Research Report No. 35. Washington DC: Food and Rural Economics Division, Economics Research Service, US Department of Agriculture, October 2003.

3 Bickel G, Nord M, Price C, Hamilton W, Cook J. Guide to Measuring Housebold Food Security, revised 2000. Alexandria, VA: Food and Nutrition Service, US Department of Agriculture, March 2000

4 Campbell CC. Food insecurity: a nutritional outcome or a predictor variable? Journal of Nutrition 1991; 121: 408-15.

5 Tarasuk VS, Beaton GH. Women's dietary intakes in the context of household food insecurity. Journal of Nutrition 1999; 129: 672-9.

6 Olson CM. Nutrition and health outcomes associated with food insecurity and hunger. Journal of Nutrition 1999; 129(Suppl. 2): 521S-4S.

7 Harrison GG, DiSogra CA, Manalo-LeClair G, Aguayo J, Yen W. Over 2.2 million Low-income California Adults are Food Insecure; 658,000 Suffer Hunger. Los Angeles, CA: UCLA Center for Health Policy Research, November 2002.

8 Blumberg SJ, Bialostosky K, Hamilton WL, Briefel RR. The effectiveness of a Short Form of the Household Food Security Scale. American Journal of Public Health 1999; 89 1231-4.

9 Simon PA, Wold CM, Cousineau MR, Fielding JE. Meeting the data needs of a local health department: the Los Angeles County Health Survey. American Journal of Public Health 2001; 91: 1950-2

10 Kasper J, Gupta SK, Tran P, Cook JT, Meyers AF. Hunger in legal immigrants in California, Texas, and Illinois. American Journal of Public Health 2000; 90: 1629-33.

11 Nelson K, Brown ME, Lurie N. Hunger in an adult patient population. Journal of the American Medical Association 1998; 279: 1211-4.

12 Gundersen C, Oliveira V. The food stamp program and food insufficiency. American Journal of Agricultural Economics 2001; 83: 875-87.

13 Gundersen C, Weinreb L, Wehler C, Hosmer D. Homelessness and food insecurity. Journal of Housing Economics 2003; 12: 250-72

14 Garcia M. Malnutrition and Food Insecurity Projections, 2020. Vision Brief 6. Washington, DC: International Food Policy Research Institute, October 1994.

15 US Conference of Mayors. A Status Report on Hunger and Homelessness in America's Cities 2000. Interagency Working Group on Food Security and Food Security Advisory Committee. Washington, DC: US Action on Food Security, December 2000. 